This item was submitted to Loughborough's Research Repository by the author.

Items in Figshare are protected by copyright, with all rights reserved, unless otherwise indicated.

\title{
A survey of virtual prototyping techniques for mechanical product development
}

PLEASE CITE THE PUBLISHED VERSION

PUBLISHER

Professional Engineering Publishing / @ IMECHE

VERSION

VoR (Version of Record)

LICENCE

CC BY-NC-ND 4.0

\section{REPOSITORY RECORD}

Zorriassatine, F., C. Wykes, Robert M. Parkin, and N. Gindy. 2019. "A Survey of Virtual Prototyping Techniques for Mechanical Product Development”. figshare. https://hdl.handle.net/2134/4706. 
This item was submitted to Loughborough's Institutional Repository (https://dspace.lboro.ac.uk/) by the author and is made available under the following Creative Commons Licence conditions.

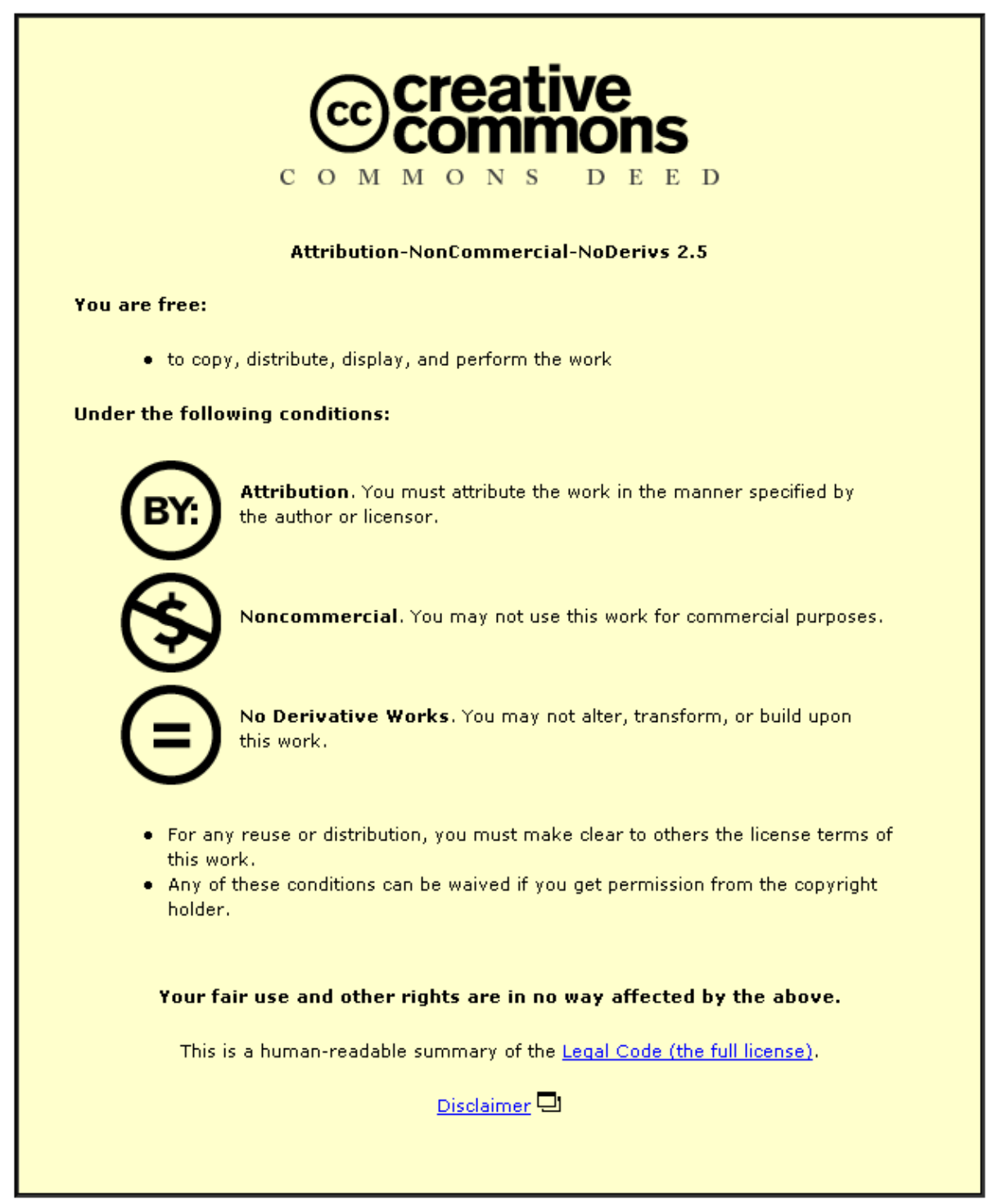

For the full text of this licence, please go to: http://creativecommons.org/licenses/by-nc-nd/2.5/ 


\title{
A survey of virtual prototyping techniques for mechanical product development
}

\author{
F Zorriassatine $^{1 *}, \mathbf{C}$ Wykes $^{2}, \mathbf{R}$ Parkin $^{1}$ and N Gindy ${ }^{2}$ \\ ${ }^{1}$ Mechatronics Research Centre, Wolfson School of Mechanical and Manufacturing Engineering, Loughborough \\ University, Loughborough, UK \\ ${ }^{2}$ School of Mechanical, Materials, Manufacturing Engineering and Management, University of Nottingham, UK
}

\begin{abstract}
Repeated, efficient, and extensive use of prototypes is a vital activity that can make the difference between successful and unsuccessful entry of new products into the competitive world market. In this respect, physical prototyping can prove to be very lengthy and expensive, especially if modifications resulting from design reviews involve tool redesign. The availability and affordability of advanced computer technology has paved the way for increasing utilization of prototypes that are digital and created in computer-based environments, i.e. they are virtual as opposed to being physical. The technology for using virtual prototypes was pioneered and adopted initially by large automotive and aerospace industries. Small-to-medium enterprises (SMEs) in the manufacturing industry also need to take virtual prototyping (VP) technology more seriously in order to exploit the benefits. VP is becoming very advanced and may eventually dominate the product development process. However, physical prototypes will still be required for the near future, albeit less frequently. This paper presents a general survey of the available VP techniques and highlights some of the most important developments and research issues while providing sources for further reference. The purpose of the paper is to provide potential SME users with a broad picture of the field of VP and to identify issues and information relevant to the deployment and implementation of VP technology.
\end{abstract}

Keywords: virtual prototyping, product development, design, modelling, simulation

\section{INTRODUCTION}

The purpose of this paper is to provide a general survey of available techniques in virtual prototyping (VP) in order to provide a broad picture of the field and to identify issues and information relevant to the deployment and implementation of VP technology. Such discussion should ultimately aid short-term as well as long-term decision making and/or planning efforts for adopting VP, especially with small-to-medium enterprises (SMEs) as the main beneficiaries in mind.

A typical scenario for product development consists of:

(a) product planning to define the product purpose and targeted market sector,

(b) conceptual design specifying intended functions and properties,

The MS was received on 6 June 2002 and was accepted after revision for publication on 29 November 2002.

* Corresponding author: Mechatronics Research Centre, Wolfson School of Mechanical and Manufacturing Engineering, Loughborough University, Ashby Road, Loughborough, Leicestershire LE11 3TU, UK. (c) detailed design to carry out and document the actual design,

(d) process planning,

(e) commissioning of the product into production.

Any problems found during or between any of the above stages will require revision of design specifications and repeating of all or some of the preceding stages. During product development, many questions need to be answered. Prototypes, by providing such answers, influence the development process. In this article, the terms 'model', 'mock-up' and 'object' all refer to the same meaning as that conveyed by 'prototype'. Successful entry of a product into the market can best occur if it can complete the above cycle in the shortest possible time and at the lowest cost while maintaining very high product quality and reliability.

The availability and affordability of advanced computer technology has paved the way for increasing utilization of digital (hence the term 'virtual'), as opposed to physical, prototypes. A virtual prototype may be represented as a series of graphical images or computer aided design 
(CAD) models, in animated or still format, created in the form of mathematical models and stored digitally in computer usable memory. VP is about presentation, testing and analysis of three-dimensional CAD models prior to creating any physical prototypes. The technology for using virtual prototypes was pioneered and adopted initially by large automotive and aerospace industries. SMEs in the manufacturing industry also need to take this technology more seriously in order to exploit the benefits that can prove crucial to their success and survival. The progressively lower prices of computer aided engineering (CAE) hardware and software and potential savings may justify the deployment of virtual prototypes.

Presently, numerous websites discuss and present the latest developments in VP. Many research papers also discuss various aspects of VP. Pratt's 1994 article [1] is one of the earliest reviews about VP with its main emphasis on integration of product realization tools. The present paper provides a fresh literature review of the state of the art of VP. Section 2 provides a classification of the available types of physical prototype that preceded and still coexist with virtual prototypes. Justification for using alternatives to physical prototypes is also given. In section 3, the main branches of VP, including their main capabilities and limitations, are discussed. Detailed explanation of each individual method is avoided where applicable, especially if valuable review papers can be offered instead. Finally, in section 4, some of the pressing issues concerning deployment of VP are presented. This paper speculates that SMEs should seriously consider moving into VP, because in the coming years their success will most likely depend on such a move.

\section{PHYSICAL PROTOTYPES}

Real material such as wood, clay, foam or metal is used to make physical prototypes, although they do not necessarily possess the same properties as those of the finished products. These prototypes can be classified into three main groups according to the possible nature of physical change used to create them. These changes, and hence their associated classes of prototypes, are described in sections 2.1 to 2.3 .

\subsection{Traditional prototypes-material removal}

Traditionally, through a variety of processes, material is continuously removed (subtracted) from an initial block. The most suitable or convenient methods and manufacturing processes may be used in any combination to create the required prototypes in one of the following ways:

1. Entirely manually using hand tools, such as carving or sculpting knives, to create objects from various materials (e.g. clay or wood) by specialist labour. Still practised examples include clay models of passenger cars and reduced scale mock-ups of largesized structures and products such as cranes, bridges and naval vessels and aircraft.

2. Using a combination of manual (including mental calculations based on interpretations by a skilled machinist of two-dimensional engineering drawings) and machining skills to operate devices such as drilling, lathe or milling machines.

3. Entirely automatically after setting up modern computer numerical control (CNC) machines to create complex and accurate shapes. The incessant advances in CNC machining have resulted in increasingly fast, more accurate, higher-resolution and precision performance, while at the same time allowing complex shape generation $[2,3]$.

\subsection{Rapid prototypes-material addition}

A recent generation of physical prototypes, using a technology known as rapid prototyping (RP), appeared first in the mid-1980s. The basis of RP (also known as solid freeform fabrication, desktop manufacturing or layer manufacturing technology) is that initially a computer three-dimensional model of the required design is created. Next, the solid or surface model to be built is converted into a digital file format referred to as STL. Subsequently, a computer program analyses the STL file to control the RP machine in producing the model. The fabrication process is accomplished by adding slices of the original model, generated from the STL file, layer upon layer until a physical model that closely resembles the original design is obtained. However, depending on the RP process in use, various postprocessing tasks may be needed in order to finish the RP model. These tasks consist of a variety of secondary processes that include removal of either untreated or excess material from the RP model. The accuracy of these models can be affected by the post-processing operations, especially if done manually. Furthermore, RP of sophisticated designs with multiple and graded materials in one unified part [4] may soon become commercially available too. A number of publications [5-11] discuss various RP developments in great depth, and numerous Internet websites provide useful information for those who wish to embark on using this rapidly evolving technology.

\subsection{Hybrid prototypes - both material removal and addition}

Recently, hybrid forms of additive and subtractive prototyping have been investigated in order to shape the parts more accurately $[\mathbf{1 2}, \mathbf{1 3}]$. The hybrid rapid prototypes combine additive RP with subtractive $\mathrm{CNC}$ 
machining. Consequently, the process planning for hybrid rapid prototypes is complicated as it involves two different technologies at the same time. The purely additive rapid prototypes are restricted to 2.5 dimensions as opposed to pure three dimensions. This is because, although additive rapid prototypes possess greater freedom of movement and hence higher resolution along the $x$ and $y$ axes, they are limited to movement in fixed increments along the $z$ axis (hence the term 2.5-dimensional). The hybrid prototypes provide better accuracy than rapid prototypes and can process the material as intended for incorporation into the finished product.

\subsection{Why also consider non-physical prototyping methods?}

The answer to the above question is that either better alternatives or improvements to the existing array of physical prototyping methods are required for many reasons, some of which are described below. It can be expensive in terms of both cost and time taken to create physical models. Despite reliability and high accuracy of $\mathrm{CNC}$, its increased time and cost over other available processes have discouraged its use, although high-speed CNC machining attempts to improve shortcomings of CNC by decreasing machining cycle times and increasing material removal rates [3]. Recent hype about RP should not create the confusion that it is the best prototyping method either. This is because RP has its own limitations. In comparison with its predecessor, i.e. the traditional material subtraction based prototyping, RP provides tremendous timesavings in making fully functioning physical models of very high complex internal and external geometry directly and automatically from CAD files. Unlike other physical prototyping methods, RP does not need expensive tooling such as dies, or any jigs or fixtures. The weakness of RP, however, is that it can fall short of the specified tolerances and surface finishes; and the required engineering materials are not always feasible for use by RP. Properties and functions of the parts produced using RP depend on the application (e.g. thermal resistance of certain polymers may not be adequate, resistance to wear is another issue). With some RP methods, physical deformation problems, such as shrinkages and warps, can pose a major drawback. In such cases, even when RP parts fit well, there is no assurance that they are dimensionally correct, as shrinkage of two or more parts in the same direction could still produce a good fit [14].

Once made, physical prototypes are either difficult or impossible to modify. In the case of precision $\mathrm{CNC}$ machining, if a prototype that has been made proves to be too small along some dimensions, e.g. after design reviews or during tests of fit and interference, it cannot be enlarged. Therefore, a new prototype has to be machined and created from a new block of material. In non-CNC production, such reviews may necessitate costly retooling of dies and castings. This drawback prohibits extensive testing of different possibilities and hinders innovation and inspiration of new design ideas because every individual prototype incurs an additional cost. It is not surprising that many companies avoid prototyping as much as possible.

Concurrent engineering (CE) is crucial to successful product development [15]. Physical prototyping greatly reduces design errors. However, owing to the inherent isolation of physical processes and resources, it does not always lend itself to implementing $\mathrm{CE}$ in an optimized manner. Team members from different engineering and non-engineering disciplines cannot simultaneously share their knowledge and often need to apply their skills sequentially with delays, and sometimes through costly iterations. In addition, data (such as dimension and quality information) are not immediately available in a central database and have to be collected or extracted, interpreted and only then communicated, and therefore inaccuracies and discrepancies may still occur, albeit at a much-reduced rate compared with product development with no prototyping.

Although the above set of reasons is not exhaustive, it nevertheless provides sufficient argument for search for better alternatives to physical prototypes. One of the important advantages of VP models is their digital nature which, coupled with much faster and affordable computer processing power, permits revision and optimization of the functionality of the designed parts in a very fast, economic and efficient manner. VP allows:

(a) greater communication, productivity and efficiency through realistic graphical modelling based on full colour, natural texture and appearance;

(b) largely reduced drawing times;

(c) dynamic viewing of models from any user-specified angle and orientation.

Hence, an examination of VP technology follows on in the next section.

\section{VIRTUAL PROTOTYPING METHODS: CLASSIFICATION, CAPABILITIES AND LIMITATIONS}

The rapid increase in both computing power and sophistication of computational methods and models of physical phenomena and the growing ability to transport results between various models are improving the scope of applications, robustness, accuracy, realism and cost effectiveness of VP technology at an incredibly fast pace [16]. VP consists of many capabilities, the best known of which is the creation and viewing of three-dimensional solid models with various colours and surface textures. A relatively large number of additional software simulation 
tools either are embedded directly into existing threedimensional CAD packages or offered by third-party vendors as add-on modules. Other familiar examples of VP include digitally generated animations of mechanisms, finite element analysis (FEA) and computational fluid dynamics (CFD) of mechanical products and structures. At a higher level, VP may even include the simulation of human users and their interactions with a product and its environment. Chang et al. [17] provide an interesting and comprehensive example of implementing VP using various commercial CAE [including CAD and computer aided manufacture (CAM)] software programs to design a simplified two-stroke airplane engine.

One way of determining the different classes of virtual prototyping tools is to examine the commercially available products. The main categories of VP tools on offer by a major supplier of a CAE family of products $[\mathbf{1 8}]$ were:

(a) mechanical design, e.g. two-/three-dimensional drafting, sketching and solid modelling;

(b) shape design and styling to address innovative forms and complex shapes such as freeform curves;

(c) analysis and simulation solutions including stress analysis, design optimization in terms of mass, displacement and principle stresses, and kinematic and dynamic simulation.

The manufacturing solutions included generation, verification, implementation and maintenance of the $\mathrm{NC}$ machine tool path. Another category by the above vendor was equipment and systems engineering which covered VP tools to handle fit and interference between three-dimensional objects, simulated walk through three-dimensional designs and system pathway definition as required by wiring or tubing within a design such as a car or a camera, and assembly trajectory of parts to identify clearances and possible collisions. Nowadays, many car manufacturers conduct virtual tests at the planning and design stages of vehicle development to study issues such as durability, crashworthiness, handling, stability, noise, vibration and harshness. Virtual testing is used to prove the quality of major components such as engines, transmissions and suspensions.

There is no standard or universal classification for VP functions (e.g. references [19] and [20]). There is even a slight difference of opinion in the way the term virtual prototyping is used. Virtual reality (VR) is one of the many VP modelling tools, inducing in the user the illusion that he/she is in the same environment as that of the model. Jasnoch et al. [21] suggest that, in the broadest sense, VP consists of three domains: VR, simulation, and manufacturing process design. On the other hand, Pratt [1] states that almost any form of computer model will serve for some purpose as a virtual prototype, and hence VP terminology should not be restricted to the domain of VR. Most of the CAE commercial packages examined also refer to digital modelling as VP, without necessarily specifying any application of VR.
Reverse engineering (RE) as an alternative to designing a new product may also be considered as an indirect type of VP activity. RE takes place by first scanning existing physical products using both fixed and portable coordinate measuring machines (CMMs) [22]. Next, the ultimate scan result is converted into a three-dimensional model that may be further processed, manipulated and even parameterized, as with any three-dimensional CAD model. In the present study, in line with the adopted terminology of the established CAE industry, VP refers to any or a combination of the CAE software applications, which rely on digital models and can be used without first building any physical prototypes.

The purposes for which prototypes are used are universal, irrespective of whether the prototype is a physical or virtual one. In general, prototypes are required for three main purposes: communication, design development, and design testing and verification [23]. Baxter [24] classified prototypes deployed during the design process into three categories:

(a) structural prototypes (used mainly to evaluate appearance, and form and fit);

(b) functional prototypes for verifying working principles;

(c) structural and functional prototypes created to examine potential preproduction and production problems.

In the previous section, physical prototypes were classified according to the nature of the physical change that is applied to create them. The VP process does not create any physical models. Thus, based on the modelling objectives and purposes, five broad classes of VP methods are identified. These classes consist of prototypes for:

(a) visualization,

(b) fit and interference of mechanical assemblies,

(c) testing and verification of functions and performance,

(d) evaluation of manufacturing and assembly operation,

(e) human factor analysis.

They are described below in sections 3.1 to 3.5. Some overlap between the elements of the above classes is not avoidable.

\subsection{Visualization models}

Visualization models are used for examination of form as well as appearance. These models play a crucial role in communication of product information between a variety of users including marketing people, customers, managers, product development teams and engineering and even repair and maintenance personnel. Visual appearance also serves as an attraction factor. Baxter [24] shows at least three aspects of product attractiveness 
that are conveyed through product appearance:

(a) attraction due to recognition of previously used products,

(b) symbolic attraction (appeal to personal and social values of customers),

(c) intrinsic attraction (inherent beauty of the product form).

Three-dimensional CAD models, which form the core of VP, are offspring from two-dimensional CAD technology. The latter started in the early 1960s and was delivered on multiuser mainframe computers in the late 1960s and early 1970s. In the mid-1970s, with the availability of three-dimensional curves and surface models, it became possible to incorporate more shape detail and complexity in the digital prototypes, allowing ever increasing realism and complexity as computer graphics and modelling developed into more sophisticated and robust techniques. Solid modelling started in the late 1960s and early 1970s and has been the preferred technique for defining three-dimensional geometry since the 1990s [25]. The existing commercial CAD software uses three-dimensional solid models to provide photo realistic images (both still and animated) that satisfy all the above appearance requirements. Visual perception and appeal can be evaluated for digital models with a variety of forms regarding product layout, describing the overall product components and subassemblies, their associated colours and surface textures and finishes.

In a two-dimensional drawing, it is only possible to show statically the order in which components of an assembly fit together. The visualization may be enhanced by using exploded or fully assembled isometric views. Isometric views are probably the clearest way within the framework of a two-dimensional environment to mimic three-dimensional views in order to communicate how the components are to be assembled together. VP visualization excels over conventional isometric representation by providing dynamic three-dimensional viewing from any angle, plus graphical animations that can be used to show a variety of situations and scenarios depending on the target audience. Examples include intended product operation for marketing and sales, and the sequence of assembling components into finished products for manufacturing engineers. Modern visualization software can simulate interactive navigation capabilities (such as variable-speed walking and flying) through complex assemblies of any size (whether microscopic or macroscopic) to enable effective and accurate visual inspection.

\subsection{Fit and interference}

In any mechanical assembly, it must be clear where and how well every subassembly or component fits with the rest of the product components and parts. Since it is impossible to manufacture components to exact dimensions,

B08102 (C) IMechE 2003 dimensional tolerances must be included in designs to allow for the inherent process variations. Fit and interference studies contribute to reducing costs of scrap and rework arising from poor fit. It can also improve part interchangeability.

Fit and interference assessment is generally an iterative, time consuming and error-prone process that would benefit from being replaced with VP using threedimensional models. Two-dimensional drawings require at least two orthogonal projections to provide sufficient geometrical information about a design. However, unlike three-dimensional models, with two dimensions it is often necessary to create very accurate physical mock-ups in order to check fit and interference. Worse still, as the complexity and number of components increase, so do the difficulty and time duration for checking fits and interferences. Using VP, the latter can be evaluated automatically with great accuracy and speed, resulting in a listing of all the interferences. It is also possible visually to inspect the virtual prototypes, where clearances and interfering areas of the CAD model can be highlighted with different colours.

Visual inspection of a digital three-dimensional assembly can be achieved using a variety of options including dynamic viewing of any part from any desired angle, or via virtual flights through the assembly, where magnified viewing allows close examination. It is also possible to verify the ability of sliding or mating parts to achieve their intended movements at each level of dimensional values within the tolerance zones [26]. Using new capabilities such as dynamic interference detection, for example, the animation of sliding mechanisms will cease, and the interference areas will be highlighted, enabling designers to identify the problematic design features.

The accuracy of VP for fit and interference checking has increased to such a high level that the Boeing 777, as the first commercial aircraft designed 100 per cent digitally with solid models, did not require any physical prototypes to obtain accurate fit [16]. During quality checks of the post-production phase, the grade of a fit for a given part feature can be determined by subjective comparison of the force required to fit two parts against the feel of a variety of standard gauges including go and not-go and plug gauges [27]. The main limitation of VP as compared with physical tests for fit and interference tests is that currently there are no commercial programs allowing such subjective examination of fit that could provide useful clues for suitability of mating parts during the virtual design stage. Increasing the power of VR with new haptic applications and interfaces (see section 4.4) may provide a solution through simulating sense of touch.

\subsection{Testing and verification of functions and performance}

Prototypes are used frequently to verify the functionality and performance of various features of a new product 
during its development phase. Virtual prototyping relies on three-dimensional solid models to create accurate models that are complete and comprehensive in terms of both detailed geometrical (e.g. centre of gravity, surface, volume) and non-geometrical (e.g. properties such as density, stiffness, etc.) data. The resulting wealth of information satisfies the data needs of advanced CAE tools for carrying out extensive and specialized tests and analysis. As for the test data, they may be either simulated or collected from previous physical testing of finished products. The latter option can provide more confidence regarding the relevance of testing data but cannot always be comprehensive enough to include all the operating conditions. Therefore, a hybrid of real and simulated data may be a more effective alternative.

Failure mode and effect analysis (FMEA) uses sets of different tests to identify and minimize potential failures and their effects on the customer [28]. In design FMEA, in particular, the system, subsystem or product at a given level of the design process and their functions must be defined, and the scope of the tests must be determined (e.g. short-term normal or extreme long-term conditions). Using computer simulation, all or parts of the possible scenarios can be simulated in order to study the behaviour of the selected functions, system or subsystems involved. Once potential failures are detected, the designed components or parts may be modified to improve their functions by eliminating any deficiencies. Alternatively, the safe operational levels for the system components or functions that are subjected to these tests can be established. Tests of this nature can be classified into three main groups as described in section 3.3. An informative discussion of an integrated CAE system to conduct VP for full-vehicle system analysis and simulation, covering vehicle durability and fatigue analysis, noise/vibration/harshness, dynamics analysis, crashworthiness, and safety analysis, appears in reference [29].

\subsubsection{Structural and physical phenomena analysis}

Finite element analysis. Finite element analysis is the most accepted and widely used VP tool. It calculates the relations between material properties and structural performance to predict the behaviour of a structure with respect to virtually all physical phenomena (see reference [30] for a detailed discussion). Using sophisticated FEA software packages, engineers can design complex structural systems and perform detailed analysis of complexities with either none or only very few physical prototypes prior to production. Without FEA, development of structures must be based on hand calculations where the simplifying assumptions can lead to conservative and heavy designs, any substantial change in designs will be risky and designs will require building of prototypes for non-destructive and destructive field tests that may also involve expensive sensors (such as strain gauging to evaluate strength and deformation).

The main applications of FEA (see references [16] and [31] for a discussion of example applications) comprise the following areas:

(a) structural integrity analysis including fatigue prediction under various loading conditions, e.g. [32] static and dynamic stiffness analysis and transient and vibration analysis;

(b) acoustics analysis: predicting and avoiding acoustics problems, for example eliminating transmission gear rattle in automotive applications;

(c) analysis of electrical and magnetic and other coupled phenomena [33].

FEA is the solution of a finite set of algebraic matrix equations that approximate the relationships between load and deflection for static analysis and velocity, and acceleration and time for dynamic analysis. The finite element method breaks down a real object into a large number of elements. The 'finite element' is a small, but not infinitesimal, part of the mechanical structure being modelled that incorporates the complex strength of material formulations into a relatively simple geometric shape. The behaviour of each small element is readily predicted by sets of mathematical equations. The summation of the individual element behaviour produces the predicted mechanical behaviour of the actual object. The simplest examples are rods, beams and triangular plates. Elements include quadrilateral plates, curved shells and three-dimensional solids such as hexahedra. Software at the high end of the price scale features extensive capabilities (such as plastic deformation and other non-linear phenomena) for simulation of phenomena such as metal forming, or crash and impact analysis (see section 3.3.2).

Generally, an FEA requires three modules [30]:

1. A finite element modeller (sometimes called a mesher or preprocessor). It generates a mesh of elements fully automatically, manually or using a hybrid of both.

2. Finite element solvers, which are the engines of FEA and use the elements, boundary conditions and loads as input in order to output a solution containing all of the information needed to review and understand results. Solvers may be divided into two categories: linear and non-linear. Linear FEA is differentiated from non-linear in that all deflections are assumed to be small, no boundary conditions change during the analysis and material properties are linear (i.e. elastic).

3. Post-processors or visualizers. These modules utilize the data generated by the solver to create more easily understandable graphics and reports.

Although FEA software tools are continually being improved, it is important to be aware of some of the problems of their use. One of the disadvantages is that 
FEA models are typically developed to analyse homogeneous materials, and they require significant user input to simulate the more complex behaviour of multiphase composites. Evaluation of design modifications and options and failure analysis are highly dependent on user skill and knowledge of finite element modelling. The cost effectiveness of FEA is heavily dependent on the meshing process, since the vast majority of human time involved in FEA can be spent on creating a suitable model for analysis. Automatic transfer from a threedimensional CAD model to mesh generation is not always problem free and requires user judgement. Mesh generation methods can be time consuming and prone to errors when applied to large or complex models, e.g. models with many faces or a large variety of shape features [34].

Computational fluid dynamics (CFD). Originating from automotive, aerospace and nuclear industries, CFD is a VP tool that is used to simulate flow and/or heat transfer for fluids (liquid and gaseous) and solids (homogenous or porous). CFD provides increasingly more reliable prediction of movement and velocity, shear, temperature and pressure contours and distribution patterns inside the systems under study. This is achieved by solving the Navier-Stokes transport equations using the conservation of mass, energy and momentum. In general, using CFD allows the design to be functionally correct in more aspects than merely the mechanical domain.

Scott and Richardson [35] provide an informative description of CFD and of what is available to any potential CFD user, including software and hardware solutions. Orszag and Staroselsky [36] provide a brief review of the state of the art in CFD and describe CFD as an effective tool that allows rapid and cost effective uncovering of fluid phenomena without relying only on physical experiments.

Some of the CFD-related shortcomings include the need to reduce the size of the total number of degrees of freedom (DOFs) of turbulence when representing some complex fields (e.g. in excess of $10^{24}$ in real-world applications such as aircraft and ships) [36]. Such critical problems will persist in spite of the phenomenal growth in the power of both computing technologies and numerical methodologies. Other more detailed consideration of complicated physics boundary conditions and multiphysics phenomena including 'phase change', electromagnetic effects and multiple phases is still required [37]. One practical way of addressing this complexity is to simplify a given problem and assess the accuracy of the results. For example, a design geometry simplification method for intelligent filtering of CAD data for a particular part or assembly and the creation of a simplified 'equivalent' for analysis purposes is used to transfer parts and assemblies to and from an airflow analysis CFD software [38]. This simplification is claimed to provide accurate and appropriate results that would

B08102 (C) IMechE 2003 otherwise take a very long time if design complexities were not simplified [39].

\subsubsection{Motion analysis}

The motion of any mechanical assembly may be modelled, evaluated and optimized in two or three dimensions. The results can be recorded using powerful animation tools and can be replayed at any time later. The two main types of motion simulation are:

1. Kinematics performance. Velocity, acceleration, position, displacement and rotation are determined without considering the mass or force properties. The main objective is to verify proper geometry of motion as intended for the design. Traces (as twodimensional objects) and envelopes (as threedimensional volumes) are used to show the path of the outline or centre of gravity of a body at various intervals during its motion. This information is useful in identifying possible interference and collisions between various parts of an assembly. It can also be used during tolerance analysis to provide integration and space requirement tests, which otherwise can only be achieved through expensive physical prototypes.

2. Dynamic motion. The main difference from kinematics simulation is that dynamic analysis considers additionally both the mass and the forces (e.g. gravity, drag and electrostatic forces) associated with the constituent elements of an assembly. Thus, detailed design information such as the power required to drive a mechanism, stiffness, safe loads, etc., can be obtained. The underlying method for calculation of the dynamics of forces and motion is the 'numerical method' [40] which is used to approximate the motion of mechanical systems by solving differential equations (using integrators such as Euler or Runge-Kutta) derived from principles of mechanics (e.g. see references [41] to [43]). Therefore, an FEA problem is subdivided into small, discrete time steps where the solution is obtained at each time step. The smaller a time step, the more accurate, but slower, the computation of motion will become. Existing commercial packages allow the users to set the level of accuracy so that a trade-off can be made to balance speed and accuracy. Using sophisticated integrators adaptively to change the step size can also significantly reduce execution time. Combining the dynamic motion simulation capability with FEA by several commercial VP tools has resulted in powerful dynamic loading simulations that provide structural behaviour (e.g. stress, vibration and noise), geometrical deformation and failure predictions. Typical applications in automotive design include suspension design, vehicle dynamics analysis, braking studies, prediction of chassis behaviour on acceleration, assessment of durability, engine design, 
timing chain design and simulation, crankshaft load prediction, powertrain engineering $[\mathbf{4 4}, \mathbf{4 5}]$ and crashworthiness tests [46].

Motion simulation objects are divided into two main groups, bodies and constraints. Bodies are shapes or CAD-drawn objects that represent a mechanism, part or assembly. Constraints generally consist of two types of object:

(a) the entities, such as revolute, pin and slot joints, that limit the degrees of freedom for movement of their associated bodies;

(b) those entities, such as springs, ropes, motors and actuators, that apply force or a torque to a body or parts of it (e.g. see references [44], [47] and [48]).

Currently, most dynamic motion simulation tools assume that each body has a mass, volume and centre of gravity while a constraint does not. Constraints are also usually left out of calculations of any collision with other constraints or bodies. Although such assumptions help to produce reasonably practical simulations, they may also cause oversimplifications that can reduce the reliability and accuracy of motion modelling.

\subsection{Manufacturing evaluation}

Ideally, virtual prototyping should comply with the requirements of concurrent engineering $(\mathrm{CE})$, as opposed to sequential engineering, and must therefore allow simultaneous product exploration and collaboration by various engineering teams. Prototype evaluation should include prediction and simulation of manufacturing processes and production planning both during the conceptual design when design data are incomplete and during the later stages when the design has matured after several design iterations. The risks of transition to full production can be reduced by integrating virtual design and testing with manufacturing simulation. The human factor analysis of manufacturing is discussed separately in section 3.5 .

\subsubsection{Manufacturability}

Manufacturability is a condition that must be satisfied before a design can be considered valid. Lack of any prototyping of the manufacturing stage heightens the risks of having to carry out design changes shortly after commissioning expensive dies, tools and other production equipment. Process planning involves selection of the type and sequence of the manufacturing operations that are needed to create a component efficiently. Once a design is expressed as a two- or three-dimensional engineering drawing, production process planning is needed to identify the optimum configuration of manufacturing processes using the most appropriate materials and running at the lowest possible cost.
Boothroyd et al. [49] discuss design for manufacture and assembly (DFMA). Greco [50] points at aspects of DFMA that will have difficulty in finding software solutions. For instance, design for variety (DFV) requires expert knowledge of products and processes, otherwise known as 'tricks of the trade', which is not easy to convert into software code. Kimura [51] provides a useful discussion of product and process modelling requirements of VP. Tseng et al. [52] report an example of VP design environment implementation where, through capture and utilization of information generated during the design phase, data for manufacturing and production and assembly planning are simultaneously generated.

After process planning, manufacturing process simulation is also needed to verify the capability of each of the manufacturing processes to achieve the desired geometry. However, as yet, such simulation does not cover all manufacturing processes. Until recently, it was mainly the machining processes that had been successfully modelled, whereas other traditional processes such as metal forming, forging, stamping, moulding and assembly had usually lagged behind the rest [1]. More recently, Hattangady et al. [53] reported that commercial packages using FEA have been very successful in the computer modelling of metal forming operations, where the workpiece mesh model is allowed to evolve to represent the material flow. They pointed out that automation of the remeshing of the workpiece, reflecting the deformations, remains a bottleneck to obtaining cost and time effective solutions. Furthermore, although the simulation of NC and CNC machining is well established, much of the present CAM technology is still limited to tool path and geometrical simulation rather than determining cutting forces and their direction.

New virtual machining systems that simulate real machining for a given set of NC codes by considering important physical properties such as cutting forces and machined surface errors already exist [54]. However, some important considerations in $\mathrm{CNC}$, i.e. chip formation, machining temperature and tool life, are not yet properly incorporated in virtual manufacturing [17]. More recently, manufacturing simulations of nonmetallic materials such as the injection moulding of plastics have become commercially available (e.g. see reference [55]). The simulation of non-traditional machining processes that are less common, including electrodischarge machining, electrochemical machining and ultrasonic machining, is not commercially available.

Fixture design is also one of the issues that must be considered during evaluation of manufacturability. Cecil [56] reviews the state of the art of computer aided fixture design (CAFD) in which the clamp, support and locator design attributes are generated automatically for the CAD solid model of a product. Cecil concludes that, in spite of the availability of numerous CAFD 
techniques, fixture design continues to be a major bottleneck in the integration of CAD and CAM and recommends the deployment of VP concepts to integrate CAFD with other product and process design techniques within CE environments.

Finally, with commercially available software packages (e.g. reference [57]) it is possible automatically to program coordinate measuring machines (CMMs) for quality control tasks prior to starting actual production. Sen and Daniel [58] illustrate how process capability studies of parametric solid models based on dimensional variability can measure the ability of a designed product to meet its specifications.

\subsubsection{Assembly analysis}

The important requirements of assembly analysis for VP are described in reference [52]. The main capabilities of existing off-the-shelf (OTS) VP tools for assembly analysis (e.g. reference [59]) include:

1. Assembly plan generation. Rules of the assembly method for feeding, grasping, orientation and insertion of all the elements are applied to evaluate assemblability and the reliability of an intended assembly system. Sequencing checks establish the order of operations through which components and subassemblies can be assembled. The exact assembly path can also be scripted into a specialized program to provide realistic parts animation, collision detection and swept volume generation and trajectory editing for clearance inspection.

2. Assembly system design. Ease of maintenance, quality control checks, reconfiguration, workplace layout and station design for all the various stages of assembly are evaluated following the generation of an assembly plan. This will include the creation and configuring of assembly stations, and operations and resources such as tooling, and fixtures can be assigned to each process on the basis of a bill-of-material structure.

Two similar research virtual assembly design environments that successfully address the shortcomings of existing computer aided assembly planning systems are reported in references [60] and [61]. The above systems make VR software and hardware accessible to expert assembly engineers. The system of Jayaram et al. [60], referred to as VADE, for example, is based neither on an interactive method of question and answer nor on automatic algorithmic assembly planning. Instead, using constrained CAD models (both in terms of geometry and assembly) within a VR environment representing the assembly area, an expert human assembler can move CAD parts and the assembly tools (e.g. fasteners and wrenches) using both hands and dexterous finger tip based manipulations to perform realistic assembly and maintenance operations. The present capabilities of VP research software (such as VADE) support a variety of
VR peripheral devices that excel those of the existing commercial VP tools because the latter have limited manipulation power when used with only non-VR interfaces, although new specialist assembly/disassembly add-on modules, offered by third-party vendors that continually enter the VP market, may have already addressed such limitations. By using VR and dynamic simulation of the behaviour of objects and the user (based on laws of physics), on-line identification of practical problems for complex assemblies and modification of CAD data while performing virtual assembly operations has become possible [60]. Although, using CAD and VR, software assembly operations involving loose-fit insertions are not difficult to simulate, simulation of force-fit insertions, e.g. in a bearing assembly, is complicated and still needs to become commercially available.

Finally, the efficiency and ease of disassembly of a product is as important as its assemblability. The ultimate purpose of disassembly is to allow maintenance and recycling. Virtual disassembly (including the disassembly sequence, tool change and the path of removal of components and fasteners) may be carried out automatically [62] or interactively, requiring extensive user input. Some research workers [63] have reported using a combination of automated reasoning and interactive disassembly of the product in a virtual environment. Owing to irreversible fastening processes, it is not always true that if a part can be disassembled it may then be assembled, and vice versa [60]. Therefore, the existing capability of commercial VP tools for assembly simulation does not necessarily guarantee successful disassembly.

\subsubsection{Manufacturing management}

Financial (e.g. the costs of implementing various manufacturing and assembly plans) and logistics and production control requirements (e.g. resource scheduling and bottleneck identification through simulation of queuing events) are the direct result of design decisions. Manufacturing management needs to evaluate the implications of these requirements prior to commissioning new products into actual manufacture. Various software, such as DFMA, use databases of assembly time standards and manufacturing process properties to estimate manufacturing costs so that optimum manufacturing processes and materials can be chosen for a given design configuration [50]. Advanced simulation tools can reflect the dynamics of the factory floor and emulate complex control mechanisms with accurate and reliable predictions such as production lead times by simulating the flow of materials and parts through constrained resources (e.g. reference [64]). Agents technology can be used to address both information modularity and the physical realities of manufacturing. Various autonomous agents can collaborate for efficient 
and effective reconfiguration of available production resources (e.g. labour, machines, facilities, material handling and inventory) for virtual manufacturing operations [65].

One of the goals during the design and development stage is to achieve low-cost production. Manufacturing management simulation tools can identify all the costs associated with a new product to allow design teams to identify and improve inefficient design features. Parametric CAD provides the required infrastructure for fast and efficient evaluation of the impact of management decisions on design changes.

\subsection{Human factor analysis}

The manufacture of a product may involve handling, assembling, packaging and maintenance by human operators. Traditionally, expensive full-size mock-ups of the product, together with either life-size human models or real users, are used to evaluate safety, ergonomics, visibility, manoeuvrability, etc. The latter, as well as other human factor aspects of manufacturing and assembly operations, can be studied extensively using VP techniques.

VP software tools using a variety of techniques including manipulation and animation of programmable virtual biomechanical manikins exist (e.g. see references [66] and [67]). These tools can be used to evaluate design alternatives, e.g. the evaluation of a work centre against common criteria including production rate, unit cost, health and safety risks, efficiency, quality measures, user friendliness, maintenance procedures and component accessibility [68-70]. In the automotive industry, examples of application of VP for assessing user-safety aspects include seat belt mechanism design, airbag deployment simulation, occupant crash simulation, prediction of driver-specific and course-specific handling response, tyre-roadway interactions including driver behaviour, controls design and braking simulation $[46,71,72]$.

Until recently, the available computer speed was insufficient to provide smooth and realistic animations, especially when the product detail and complexity were high. Simple two-dimensional and three-dimensional motion simulations are not adequately flexible to provide accurate and useful feedback for ergonomics studies. However, with the increasing availability and affordability of very powerful dedicated graphics workstations, large computer memory and more efficient and sophisticated software algorithms that avoid tying down the computer processing power with unnecessary model details, the aforementioned problem will become much less of an issue. Integration of VP with VR is enabling user interactions with three-dimensional models that are more realistic (see section 4.4). Thus, better representation of the behaviour of physical objects under simulated real-world conditions and physical laws such as gravity, friction, stiffness, etc., is becoming possible [73]. Paradigms for investigations and natural experimentation using VR and VP, especially regarding the verification of assembly and maintenance processes, can be found in the literature [74, 75].

Ultimately, evaluation of human factor aspects can reveal faults, which are then propagated back either automatically (via new parametric values of design features) or manually (as modified product specifications) up along the design stream. Seamless integration of CAD with methods engineering [76] and other human factor analysis tools is available commercially. However, automatic and speedy correction of design faults after performing such analysis requires customization of the OTS software.

\section{DISCUSSION}

Despite its acclaimed successes, there are reports of limitations of the present VP systems. Chua et al. [19], for example, report about a company that found VP be unable to 'simulate process problems efficiently and effectively'. The accuracy of FEA was also said to be limited 'because of the inconsistent behaviour of material', etc. In reporting another example of problems with VP, the above authors point at the lack of any tactile feeling (e.g. in relation to the design of keypads) and inadequate visualization for viewing the assembly of some components (e.g. PCBs inserted at an angle). It is therefore necessary to shed some light on some of the important issues likely to be encountered during deployment of VP.

\subsection{Three-dimensional versus two-dimensional representation}

VP has been used in product design and development since the 1970s [14]. Effective VP, especially for detailed design, cannot be accomplished without using threedimensional models. The latter have progressed from wireframe and surface models into solid models. The flexibility and power of solid models have also continually developed from parametric to constraint-based and finally to feature-based modelling. In comparison with two-dimensional modelling, the solid models are capable of incorporating more unified information which enables them to provide increased potential for model interpretation and analysis [1]. Although two-dimensional models also represent simplified models of a product, many prototyping activities will be inferior to non-virtual alternatives if they are limited to only two-dimensional representation. Yet, a survey of CAD users in the mechanical engineering sector of the United Kingdom [77] indicated that only just over half (51 per cent) use three-dimensional CAD. However, 68 per cent of the 
companies that use two-dimensional CAD said they have no plans to adopt three-dimensional CAD. The findings of an earlier survey of US CAD users in 1999 [78] had also shown the dominance of two-dimensional usage, although a great percentage of the user companies sampled (75 per cent) wanted to upgrade to three dimensions. A greater awareness of the potential benefits of three-dimensional solid modelling may encourage more manufacturing companies to exploit VP.

\subsection{Conceptual design tools}

VP tools that are limited to the detailed design phase (for instance, requiring precise three-dimensional models) can result in wasted time and effort for detailing designs that may not work. This limitation arises owing to the imprecise and incomplete nature of design knowledge and requirements at the early phases of a product life cycle.

Recently, research has begun to tackle some of the challenges to pave the way for realization of computer aided conceptual design [79]. Dynamic motion analysis, for instance, is offered commercially at both conceptual and detailed levels of design. Some of the latter tools are dedicated to the conceptual design of specific types of critical component (e.g. aircraft landing gear [80]) using models created by a variety of techniques such as linking graphical symbols representing various properties and functions and without requiring any engineering drawings as input. Other dynamic analysis tools can be more general and applicable to a wider variety of mechanical parts using simplified two-dimensional CAD models sketched by the users (e.g. reference [47]). However, most other CAE tools tend to be applicable only to improving detailed design and detailed manufacturing planning and until recently have been far from satisfactory for conducting integrated conceptual design and process planning and manufacturing analysis [81].

\subsection{Prototyping accuracy}

Accuracy of prototyping depends on faithful simulation of all the factors representing the product and its intended operating environment. Such factors include product specified geometry, functions and performance and the intended fabrication technology, as well as the human users and their interaction with the product. A high level of detail must be incorporated in a digital model to achieve accurate virtual prototypes. The accuracy of all the analytical processes and models need to be assessed to measure the correlation between predicted results and the corresponding physical equivalents. Some studies provide examples of how such measurements can be achieved. Examples of these include assessment of the quality of CFD in order to identify opportunities for improving the modelling accuracy of automotive engine cooling systems [82], and comparison of actual and simulated structural deformations (see references [32] and [83]). Miller [16] presented an illustrative examination of the limitations and capabilities of VP modelling and simulation with respect to three case studies in the US aircraft industries and found that the accuracy of VP was either equal to or higher than its traditional engineering alternatives. However, as the following discussion shows, there are still many aspects that require further improvement.

Geometry is created in finite (as 'single' or 'increased') precision, depending on the CPU hardware in use. On most systems, geometry is mathematically stored between 7 to 16 significant digits, although the number of digits displayed is smaller than the actual value. This finite precision of the floating-point number forces geometry algorithms to converge to some epsilon rather than the absolute zero required by mathematical theory [25]. Consequently, depending on the algorithm being used, different CAE (and especially CAD) programs can produce different results (e.g. in fit and interference analysis), although the difference may not always be apparent. Kasik [25] predicts that new computing techniques (e.g. neural, quantum and optical) will support more reliable algorithms than the current silicon-based technology.

A factor crucial to the success of VP is that CAD/CAE software must make more comprehensive use of both functional and manufacturing features [84] and parametric modelling (i.e. dimensional and geometrical constraining of product features). Libraries of design features, and reuse and scalability of design instances found in such libraries, can greatly reduce the design cycle time. Such data can be compiled from archives and histories of objects modelled in $\mathrm{CAD} / \mathrm{CAM} / \mathrm{CAE}$ systems, as well as through automatic feature recognition and updating when new objects are developed [85].

New materials as well as new manufacturing processes are also being developed all the time. The production prototype for manufacturing a new part, e.g. using a new rotary forging operation, must be produced by means of a manufacturing virtual prototype that closely resembles the actual nature of the manufacturing operation. The manufacturing simulation tools are not yet fully linked to the design models. This can either prevent or slow down the automatic translation of the problems identified during manufacturing simulation into the required $\mathrm{CAD}$ modifications. $\mathrm{CE}$ in its true sense should not allow a significant gap between the various phases of product realization, e.g. between design and manufacture. Therefore, as far as most SMEs are concerned there is a need for the development of manufacturing and assembly simulation modules that can simulate a large range of possible operations.

The testing of designs in rare conditions that are extremely difficult or impossible to mimic and where human life is at stake is another area that needs 
improvement. Although virtual prototypes are becoming progressively more advanced and powerful, there is still a gap between physical testing and virtual testing. Simulation programs are still not relied upon with 100 per cent confidence. One of the requirements of simulation is to convert simulated data to subjective data (e.g. driver comfort in a virtual car) in order to evaluate a design. Consequently, physical test rigs that simulate the environmental conditions are still used to act as a bridge to link full-scale physical testing and virtual testing. For instance, the final commissioning of space vehicles into operation relies on actual physical 'drop tests' from an aircraft to simulate flight conditions similar to those encountered by a re-entering craft.

\subsection{User interfaces and interaction techniques}

As the interfaces and interaction techniques are being continually developed, VP designers and users are moving closer to more efficient and effective model manipulation. A still evolving method for product visualization is the three-dimensional display of solid models using laser holography which is meant to address the shortcomings of two-dimensional display screens but is still far from satisfactory [86]. More model manipulation power is being provided with the availability of recent innovations such as:

(a) three-dimensional mice held in the air above the desktop;

(b) three-dimensional motion controllers (e.g. see reference [87]);

(c) two-handed controls that allow the user to mimic push, pull and twist motions using a combination of a standard mouse and an additional hand-held sensitive ball or cap devices.

However, more effective user interfaces with higher resolution and greater degrees of freedom are still required [74]. To date, VPs are mainly visualized on computer screens. Another alternative is that, once designed, virtual engineering components and objects may be manipulated by immersing the users in computer-simulated environments to provide them with better model viewing and manipulation power. Ideally, a designer must be able to interact with a virtual environment that allows the touching and feeling, movement and even modification of a virtual prototype with similar realism to that experienced during examination of a physical prototype [88].

The above-mentioned improvement in model manipulation and examination can be achieved through VR and the use of a new generation of interface devices and their specialist programming tools. Examples of these interfaces include data gloves, which allow movement through virtual worlds by combining hand gestures with the pitch and roll of hands, and head-mounted displays, which continually update the simulation to reflect a new perspective as the user's head moves forwards, backwards or sideways, or as he/she looks in different directions. Cubicle interfaces known as CAVEs [89] are also a recent VR innovation. However, currently for many potential users they may prove to be too expensive to use. CAVEs provide a greater sense of immersion without needing helmets or viewing boxes, and using a much larger field of view by projecting data in stereoscopic images onto the walls and floor of the interface. Utilization of haptic interfaces allows simulation of touch and feel, precision positioning input and high fidelity, and force feedback output for virtual objects. With the commercial availability of haptic interfaces [90], programs dedicated to simulation of laws of physics that handle complex computations, thus freeing developers to deal with high-level objects and physical properties such as location, mass, friction and stiffness [91], and application programs [92, 93], VR can provide realistic sensory feedback models for performing assembly analysis and general product evaluation. Gomes de Sa and Zachmann [74] discuss both the application of VR in VP systems and the integration of CAD with VR. Simulation of weight and stiffness, which can improve VR effectiveness in VP applications, has not been reported.

Some researchers $[\mathbf{9 4 , 9 5}$ ] maintain that pure VP may reduce cognition and communication. Balet et al. [94] argue that lack of correlation between manipulation and effect and the great distance between the mental image assumed by the user and that of the edited models are the major drawbacks of systems that manage three-dimensional environments via twodimensional GUIs. Therefore, full three-dimensional interfaces such as VR may not always be appropriate, and instead it is more useful to create mixed interfaces to interact with articulated three-dimensional objects such as pipes, wires and human bodies. An in-depth discussion of the new possibilities for product realization that arise from the combination of virtual and real models can be found in reference [96].

\subsection{Task automation}

In its present commercial OTS form, virtual prototyping is still not fully automated since there is still a need for interpretation and feedback of various modules higher up or lower down the design stream from any given prototype. A browse through various Internet sites will quickly reveal that new specialist modules aimed at particular products or sectors of manufacturing industry are continually arriving in the software market as add-on modules to enhance the capabilities of existing commercial VP systems. VP requires mastery of the software and the ability of trained users to configure/ integrate systems and interpret their prototyping results. 
Therefore, for typical SME companies, a move towards VP is more than just purchasing VP software and then expecting results. A significant amount of human involvement is still required, thus making successful implementation of VP sensitive to the level and quality of user competence and interpretation skills. Awareness of the current problems and limitations, and issues such as occasional training, must be accompanied with commitment to frequent investment continually to update both systems and users skills and knowledge.

Currently, users of VP systems need to possess competence in engineering as well as enjoying sufficient understanding of the infrastructure of their VP software tools. Physical systems with highly complex and nonlinear structures require very sophisticated and highly integrated software tools and management in order to monitor large numbers of interactions between various subsystems and their prototypes. The present authors' experience of using modern CAE systems has shown that some understanding of the hierarchical nature of object-oriented software systems could improve the learning curve and user competence. With the availability of scripting languages, the automation of VP tasks is becoming more feasible, although technical expertise, including software programming, will be required.

\subsection{Tools integration and product life cycle management}

Successful VP requires comprehensive integration of and communication between various analysis tools so that new products are designed with inputs from all concerned. This in turn requires easy data conversion and compatibility. An integrated approach to product design and assembly planning is crucial for achieving true CE. A variety of the existing commercial CAE tools that can facilitate product design and planning, together with their implementations, are discussed in references [97] and [98].

Prior to any computer implementation, however, steps are required to ensure data compatibility. Pratt [1] provides an informative discussion of the required interface between various VP models. A detailed discussion of the tool integration requirements and techniques for conducting VP is given in reference [99]. The latter suggests the use of parameterized CAD and non-CAD product data models representing engineering data, product views from the perspectives of various engineering disciplines, two-way data translation and transmission between engineering tools and product data models, and design process management to monitor and manage design process and its infrastructure. Although CAD standards such as PDES/STEP are improving the robustness of geometry descriptions and translation accuracy over other older standards (such as IGES), moving data from one CAD application to another will be problematic as long as different geometry implementation algorithms are being used [25].

Product data management (PDM) systems encompass the integration and management of processes, applications and information. PDMs aim to resolve the problem of 'islands of automation' in order to support CE by providing a collaborative environment. Features enable various processes to share information across the spectrum of the product development cycle (i.e. between design, analysis and manufacturing). Successful integration of VP tools relies on feature modelling as a key enabling technology. Ovtcharova and Vieira [100] provide a detailed discussion. Greipel and Colpaert [101] also show how an object-oriented and application-independent approach coupled with modern intelligent user interface techniques can further extend the potentials of feature-based and parametric modelling. PDM systems use features to integrate CAD and simulated functional data in order to add intelligence to graphic representations of a product. Intelligent CAD systems enable better understanding of the real requirements of a product and determination of its key parameters. CAD intelligence is provided in the form of a wide range of additional information including behaviour and performance related to final assembly, operation and maintenance. This information is in addition to the already existing dimensional, geometrical and kinematic data. PDMs should enable engineers and other users to search design models that are updateable in real time, and reuse knowledge and company best practices by combining artificial intelligence techniques such as neural networks and expert systems with CAD and object-oriented databases [102-104] and agentbased technology $[\mathbf{1 0 5}, \mathbf{1 0 6}]$. Although PDMs are available as commercial systems and being used by large enterprises, they are still not fully flexible, are difficult to implement and customize and therefore need further improvement to mature.

Product life cycle management (PLM) considers the product life cycle (consisting of design, manufacture, use and finally disposal of a product) as a whole and optimizes the interaction of product design, manufacturing and life cycle activities in order to protect energy, material, information, physical and human resources and maximize effectiveness during their usage. Product structure and composition can be read from the CAD or a PDM system and charted as a tree model with all assemblies and components in order to predict both short-term and long-term costs such as production and material costs and tool and investment costs for different design alternatives. Other factors such as reliability, availability and maintainability may also be evaluated. The goals of PLM may be achieved by means of PDM, life cycle assessment [107], technical support and life cycle costing [108].

The existing approaches to PLM and their visions and further development are discussed in reference [109]. The 
environmental impacts of product life cycles are discussed in reference [110]. A generic template for deployment of PDM as the framework to integrate VP applications, cross-functional teaming and information integration to allow sharing and discussion of ideas from the outset of a product life cycle by different product development teams can be found in reference [111]. Andert and Morgan [112] provide an example of collaborative VP in naval engineering. Collaborative design does not merely involve a technical decision-making process. A comprehensive methodology to model and analyse sociotechnical interactions between all the various teams and their conflicts is discussed in reference [113].

As companies move more into adopting full and integrated VP, the management and storage of large amounts of information become even more critical issues. Therefore, the importance of realizing cost effective and efficient model scalability, data warehousing and knowledge reuse, data confidentiality and security, and data storage and maintenance (i.e. updating, reformatting and revalidating to make existing design models usable with continuously evolving software and hardware product) is growing rapidly. Such growth is especially critical for the frequently occurring new design versions, specifically with respect to large and/or complex products as found in the automotive, aircraft and naval industries. On the other hand, SMEs and manufacturers of less complicated products and components can look forward to an immediate benefit from the increasing availability and affordability of cheaper and yet very powerful CAE software and hardware.

Using CAE analysis tools effectively requires deep understanding of their theory and practice. Nowadays, user-friendly, and increasingly more graphics- than text-based, OTS CAE tools allow designers in a company, who may not be specialists in CAE, to conduct preliminary and what-if studies of their designs to highlight potential problems during the conceptual design stage. Currently, the next step for SMEs that seek to produce high-quality products may still be to contract out the optimization of detailed design of their overall products or systems to specialist CAE consultants.

\subsection{Virtual prototyping and the Internet}

Internet and Intranets capability enables communication of accurate and up-to-date product information through text, two/three-dimensional images and drawings and multimedia. This capability relies on networks that run transmission control protocol (TCP) and Internet protocol (IP) standards to enable cross-platform data communication irrespective of the type of computer platforms, operating system, application programs or geographical locations of the users. Using Internet technology such as platform independent plug-in
JAVA [114] programs and three-dimensional viewing based on VRML file formats allows members of various engineering teams to review, annotate, visualize or interact in real time and simultaneously with virtual prototypes using a standard Web browser (e.g. references [115] and [116]).

Moreover, installing an expensive CAE program on the client workstations is no longer required as dedicated and powerful CAE Web-servers that contain most of the software modules can send only the minimum number of necessary programs to the client browsers (e.g. as JAVA applets). Thus, the servers will perform tasks depending on requests made from the client browsers. Web-based CAE services are increasingly on offer from leading CAE and CAD vendors.

The sharing of data over the Internet may, depending on the application software being used, range from simultaneous viewing and annotation to user interaction with the model according to the user's rights and network system configuration. The role of standards for geometric models, such as STEP/IGES for product three-dimensional data interchange between client and server computers, has been discussed by many researchers, e.g. by Gadh and Sonthi [117]. STEPbased browsers offering more powerful manipulation than the existing information-reducing VRML formats are emerging. Hyperlinking (the ability to link electronically interrelated pieces of information) is being extended from text and raster images to vector CAD files through new vector file formats such as DWF and CGM. An example virtual collaboration system that allows designers of a DDG-51 destroyer ship to share virtual prototype simulations across an IP network is given in references [112], using low-cost PC workstations (both high and low performance) and specialized graphics and communication servers. The new trend in CAE Web information publishing is to move from predetermined static formats (otherwise known as 'push' technology) into dynamic and synchronized 'pull' technology where all the information is kept current all the time (e.g. see reference [118]).

\section{CONCLUSION}

Modern physical prototyping (e.g. high-speed CNC machining and RP) and virtual prototyping techniques continue to advance and become more powerful. The question is which options are most appropriate? Various criteria, including physical, operational and application considerations, need to be satisfied by the chosen prototyping methods. These requirements include (though are not limited to) time, cost, material properties, modelling accuracy and reliability, size, quality, level of detail, etc. The existing VP and non-VP methods may or may not satisfy such requirements depending on the design requirements. Therefore, the merits of each option need 
to be assessed against the individual requirements of each enterprise and its specific products. Ultimately, the ideal prototyping solution, whichever form it may take, is the one that can quickly, and accurately, generate a design that will have high quality and low production cost in the shortest time.

Although VP is already well established in the automotive and aerospace industries, many SMEs still cast doubt on the practicality and benefits of VP and favour physical prototypes if any at all. This paper has attempted to support the belief that it will be hard to reject the great probability that VP will become the most promising prototyping solution. VP has reduced the required number of physical prototypes in many fields of engineering, especially in the aerospace and automotive industries, which are at present the main visionaries and pioneers of VP.

In the quest for fast and economic product development, some forms of physical prototype will still be required for the near future, albeit with a rapidly decreasing degree of frequency. Special emphasis must be kept on using RP, which complements VP for modelling purposes. The latter mainly include proof of concept through verification of expected functioning of a design, or creation of final tooling (such as dies and investment castings) prior to going into production phase. Most of the VP simulations and studies such as FEA, dynamic motion analysis and fit and interference checks are capable of providing equally, if not more, reliable and accurate predictions compared with their RP counterparts. Virtual testing of prototypes is still evolving, while physical testing is proven and reliable [119]. A comprehensive study of all the major prototyping options needs to be carried out in the future, especially when VP tools will have reached a high degree of maturity. Such study would provide the much-needed benchmarks to allow independent and objective comparisons of available alternatives. Any such research will be a major undertaking, as it would have to reveal the accuracy, reliability and risk information for different prototyping strategies.

Ideally, once the extensive simulations of virtual prototypes are over, it must be possible to build the final product right first time and with no safety risks or product failures. In spite of its great achievements and widespread use by large aircraft and automotive manufacturers, it seems that the existing limitations of VP technology have not permitted the full realization of the above ideal. Some requirements of product development, which are in need of automation and therefore further research, will continue to prevent the full potential of virtual prototyping from minimizing product time-to-market. VP solutions that cannot make their output information available to other applications reduce the transparency and speed of the impact of changes in the product structure. One such obstacle is the difficulty of automatic translation of detailed designs into appropriate process plans for production of final products.

In the coming years, adoption of state-of-the-art virtual product development methods can play a crucial role in industrial success. In spite of the difficulties and shortcomings of VP, SME manufacturers will need continually to stay abreast of developments on its great capabilities and benefits, and prepare themselves for commitment to its adoption. This will include implementation of associated technical and organizational changes.

The implementation of VP is more successful and less difficult to achieve at component level than at system level because the latter necessitates comprehensive modelling of complex interactions between constituent subassemblies and components. VP at the system level may only be achieved with full integration of product and process data, although it can be expensive in the short term. However, integration can give long-term dividends through more effective VP solutions. SMEs deal with a smaller number of components, and often less complicated product structures, and consequently require a more limited range of situations to simulate and test their products and processes. Compared with larger manufacturers, this might mean that SMEs will face fewer risks. Hence, they can have more confidence to consider utilizing VP technology for product development. Stand-alone VP tools may not be as efficient as fully integrated systems. However, if the product is complicated enough, even the more affordable stand-alone VP can still provide powerful and cost effective solutions, especially if the latter can replace expensive physical prototypes. In the past, and judging by the commercial catalogues and literature, VP vendors have created custom add-on solutions mainly for their larger clients (i.e. the automotive and aerospace industries). These vendors should increasingly also cater for the more general-purpose and at the same time limited (and thus more affordable) solutions suitable to the needs of other sectors of the manufacturing industry. Increased customization and parameterization capability, wider integration with existing CAD solutions, greater adaptability to diverse business aspects of manufacturing enterprises, enhanced visualization of digital reviews, more realistic consideration and modelling of the constraints imposed by physical laws, more user-friendly interfaces, ever-growing storage capacity, accelerating processing speed and affordable software prices will eventually pave the way for widespread adoption of VP solutions.

\section{ACKNOWLEDGEMENTS}

The authors thank the UK Government's Department of Trade and Industry and the PRIME Faraday Partnership (http://www.primefaraday.org.uk/) for sponsoring this research. 


\section{REFERENCES}

1 Pratt, M. J. Virtual prototypes and product models in mechanical engineering. In Virtual Prototyping-Virtual Environments and the Product Design Process (Eds J. Rix, S. Hass and J. Teixeira), 1995, pp. 113-128 (Chapman and Hall, London).

2 Schmidt, J. W. CNC machining - the other rapid prototyping technology. In Proceedings of 1997 International Congress and Exposition. SAE Special Publs, 1997, 1233, 89-91.

3 Schmitz, T., Davies, M., Dutterer, B. and Ziegert, J. The application of high-speed CNC machining to prototype production. Int. J. Mach. Tools and Mf., 2001, 41, 12091228.

4 Bhashyam, S., Shin, K. H. and Dutta, D. An integrated CAD system for design of heterogeneous objects. Rapid Prototyping J., 2000, 6(2), 119-135.

5 Chua, C. K. and Leong, K. F. Rapid Prototyping-Principles and Applications in Manufacturing, 1997 (John Wiley, Singapore).

6 Onhu, S. O. and Yusuf, Y. Y. Rapid prototyping technology: applications and benefits for rapid product development. J. Intell. Mfg, 1999, 10, 301-311.

7 Wiedemann, B. and Jantzen, H.-A. Strategies and applications for rapid product and process development in Daimler-Benz AG. Computers in Industry, 1999, 39, 11-25.

8 Xu, F., Loh, H. T. and Wong, Y. S. Considerations and selection of optimal orientation for different rapid prototyping systems. Rapid Prototyping J., 1999, 5(2), 54-60.

9 Grimm, T. SLS and SLA: Different Technologies for Different Applications, 1996 (Accelerated Technologies, Inc., USA); http://www.atirapid.com/news/ar_slssla0596.html.

10 Pham, D. T. and Gault, R. S. A comparison of rapid prototyping technologies. Int. J. Mach. Tools and Mf., 1998, 38, 1257-1287.

11 Wholers, T. Wholers Report 2001; Executive Summary, 1st edition, 2001 (Wholers Associates, Inc., Colorado); http:// www.wholersassociates.com/.

12 Ramasmawi, K. Process planning for shape deposition manufacturing. PhD thesis, Department of Mechanical Engineering, Stanford University, 1997.

13 Merz, R., Prinz, F. B., Ramaswami, K., Terk, M. and Weiss, L. Shape deposition manufacturing. In Proceedings of Solid Freeform Fabrication Symposium, University of Texas at Austin, 8-10 August 1994.

14 Binnard, M. Design by Composition for Rapid Prototyping, 1999 (Kluwer Academic Press, Boston, Massachusetts).

15 Finger, S., Stivoric, J., Amon, C., Gursoz, L., Prinz, F., Siewiorek, D., Smailagic, A. and Weisss, L. Reflections on a concurrent design methodology: a case study in wearable computer design. Computer-Aided Des., 1996, 28(5), 393-404.

16 Miller, D. E. Modeling and simulation technology - a new vector for flight-tests. Master's thesis, School of Advanced Airpower Studies, Air University, Maxwell Air Force Base, Alabama, 1998.

17 Chang, K.-H., Silva, J. and Bryant, I. Concurrent design and manufacturing for mechanical systems. Concurrent Engng: Res. Applic., 1994, 7(4), 290-308.

18 CATIA, Dassault Systemes, France, 2002; http:// www.3ds.com/.
19 Chua, C. K., Teh, S. H. and Gay, R. K. L. Rapid prototyping versus virtual prototyping in product design and manufacturing. Int. J. Advd Mfg Technol., 1999, 15, $597-603$.

20 Waterman, P. J. Digital prototyping. Desktop Engng, November 1998 (on-line edition, http://www.deskeng. com/articles/98/November/COV/cov1198.htm).

21 Jasnoch, U., Kress, H. and Rix, J. Towards a virtual prototyping environment. In Proceedings of IFIP WG 5.10 on Virtual Environments and Their Applications and Virtual Prototyping, 1994, pp. 173-183.

22 Thompson, W. B., Owen, J. C., de St. Germain, H. J., Stark, S. R. and Henderson, T. C. Feature-based reverse engineering of mechanical parts. IEEE Trans. Robotics and Automn, February 1999.

23 Black, R. Design and Manufacture-An Integrated Approach, 1996 (Macmillan Press, London).

24 Baxter, M. Product Design: A Practical Guide to Systematic Methods of New Product Development, 1995 (Chapman and Hall, London).

25 Kasik, D. J. Viewing the future of CAD. IEEE Computer Graphics and Applic., January/February 2000, 20(1), 34-35.

26 Moving from $2 D$ to $3 D C A D$, the Productivity and Business Advantages, Unigraphics Solution, USA, 2002; Solidedge@ugsolutions.com.

27 Lissaman, A. J. and Martin, S. J. Principles of Engineering Production, 2nd edition, 1982 (Hodder and Stoughton, London).

28 Ranky, P. G. Concurrent/Simultaneous EngineeringMethods, Tools, and Case Studies, 1994, pp. 89-105 (CIMware Limited, Guildford).

29 Zhang, Y., Tang, A., Palmer, T. and Hazard, C. Virtual proving ground - an integrated technology for full vehicle analysis and simulation. Int. J. Veh. Des., 1999, 21(4/5) (Special Issue), 450-470.

30 Hughes, T. J. R. The Finite Element Method: Linear Static and Dynamic Finite Element Analysis, 2000 (Dover Publications, USA).

31 Cook, R. D., Malkus, D. S., Plesha, M. E. and Witt, R. J. Concepts and Applications of Finite Element Analysis, 4th edition, 2001 (John Wiley, New York).

32 Kim, H. S. and Huh, H. Vehicle structural collapse analysis using a finite element limited method. Int. J. Veh. Des., 1999, 21(4), 436-449.

33 Desmet, W., Sas, P. and Vandepitte, D. An indirect Trefftz method for the steady-state dynamic analysis of coupled vibro-acoustic systems. Computer Assisted Mechanics and Engng Sci., 2001, 8(2-3), 271-288.

34 Liu, S.-S. and Gadh, R. Basic logical bulk shapes (BLOBs) for finite element hexahedral mesh generation to support virtual prototyping. Trans. ASME, J. Mfg Sci. Engng, 1998, 120, 728-735.

35 Scott, G. and Richardson, P. The application of computational fluid dynamics in the food industry. Trends in Food Sci. Technol., April 1997, 8, 119-124.

36 Orszag, S. A. and Staroselsky, I. CFD: progress and problems. Computer Phys. Commun., 2000, 127, 165-171.

37 Peric, M. The future of CFD. MCAD, May 2002, 22, 45.

38 Flo/MCAD, Flomerics, Inc., USA, 2002; http://www. flotherm.com/prod_info/flomcad/.

39 Dean, A. Flotherm-upfront CFD for the masses. $M C A D$, March 2002, 22, 51. 
40 Golub, G. H. and Ortega, J. M. Scientific Computing and Differential Equations: An Introduction to Numerical Methods, 1992 (Academic Press, USA).

41 Myszka, D. H. Machines and Mechanisms-Applied Kinematic Analysis, 1999 (Prentice-Hall, Englewood Cliffs, New Jersey).

42 Haug, E. J. Computer-Aided Kinematics and Dynamics of Mechanical Systems, 1989 (Allyn and Bacon, Boston, Massachusetts).

43 Kane, T. R. and Levinson, D. A. Dynamics: Theory and Applications, 1985 (McGraw-Hill).

44 Mechanical Event Simulation $^{\mathrm{TM}}$, Algor, Inc., USA, 2002; http://www.algor.com/.

$45 A D A M S^{\circledR} /$ Car, Mechanical Dynamics, Inc., USA, 2002; http://www.adams.com/.

46 Schulz, M., Ertl, Th. and Reuding, Th. Crashing in cyberspace - evaluating structural behaviour of car bodies in a virtual environment. In Proceedings of 1998 IEEE Virtual Reality Annual International Symposium, Atlanta, Georgia, 1998, pp. 160-165.

47 Working Model 2D ${ }^{\mathrm{TM}}$ Users Manual, 1999 (Knowledge Revolution, California).

48 MSC.visualNastran Desktop 2002 $2^{\mathrm{TM}}, 2002$ (MSC.Software Corp., USA); http://www.krev.com/2002/welcome.html.

49 Boothroyd,G., Dewhurst,P. and Knight, W. Product Designfor Manufactureand Assembly, 1994(MarcelDekker,New York).

50 Greco, J. Design for manufacturability and assembly. MCADVision, September Feature Issue 2000; www. MCADCafe.com.

51 Kimura, F. Product and process modelling as a kernel for virtual manufacturing environment. Ann. CIRP, 1993, 42(1), 147-150.

52 Tseng, M. M., Jiao, J. and Su, C.-J. Virtual prototyping for customised product development. Integrated Mfg Syst., 1998, 9(6), 334-343.

53 Hattangady, N. V., Shephard, M. S. and Chaudhary, A. B. Towards realistic automated 3D modelling of metal forming problems. Engng with Computers, 1999, 15, 356-374.

54 Ko, J. H., Yun, W. S. and Cho, D.-W. Off-line feed rate scheduling using virtual CNC based on an evaluation of cutting performance. Computer-Aided Des., April 2003, 35(4), 383-393.

55 MoldFlow's Plastic Adviser $^{\mathrm{TM}}$, Moldflow, USA, 2002; http://www.moldflow.com/Products/MPA-/index.htm.

56 Cecil, J. Computer-aided fixture design - a review and future trends. Int. J. Advd Mfg Technol., 2001, 18, 790-793.

57 INSPECT TM , Delmia Corporation, USA, 2002; http:// www.delmia.com.

58 Sen, J. K. and Daniel, J. M. Design and manufacturing efficiencies through modelling and simulation in IPPD. In Proceedings of 55th Annual Forum of the American Helicopter Society, Montreal, Canada, American Helicopter Society, 25-27 May 1999, Vol. 1, pp. 36-45.

59 DPM Assembly ${ }^{\circledR}$, Delmia Corporation, USA, 2002; http://www.delmia.com.

60 Jayaram, S., Jayaram, U., Wang, Y., Tirumali, H., Lyons, K. and Hart, P. VADE: a virtual assembly design environment. IEEE Computer Graphics and Applic., November/ December 1999, 44-50.

61 Gupta, R., Whitney, D. and Zeltzert, D. Prototyping and design for assembly analysis using multimodal virtual environments. Computer-Aided Des., 1997, 29(8), 585-597.
62 Lee, K. and Gadh, R. Destructive disassembly to support virtual prototyping. IIE Trans., 1998, 30, 959-972.

63 Siddique, Z. and Rosen, D. W. A virtual prototyping approach to product disassembly reasoning. ComputerAided Des., 1997, 29(12), 847-860.

64 Quest $^{\mathbb{R}}$, Delmia Corporation, USA, 2002; http:// www.delmia.com.

65 Baker, A. D., Van Dyke Parunak, H. and Erol, K. Agents and the Internet: infrastructure for mass customisation. IEEE Internet Computing, September-October 1999, 62-69.

66 Ergonomics Design and Analysis ${ }^{\mathrm{TM}}$, Dassault Systemes, France, 2002; http://www.catia.com/.

67 Envision/Ergo $^{\mathrm{TM}}$, Delmia Corporation, USA, 2002; http:// www.delmia.com.

68 Jack Software User Guide-Version 5.8, 1994 (Computer Graphics Research Laboratory, Department of Computer and Information Science, University of Pennsylvania).

69 Deitz, D. Human-integrated design. Mech. Engng, 1995, 17(8), 92-96.

70 Porter, J. M., Freer, M., Case, K. and Bonney, M. Computer aided ergonomics and work-space design. In Evaluation of Human Work (Eds J. R. Wilson and E. N. Corlett), 2nd edition, 1995 (Taylor and Francis, London).

71 MSC.Dytran ${ }^{\mathrm{TM}}$, MSC Software, USA, 2001; http:// simulate.engineering-e.com/misc/simgeneral.pdf.

$72 A D A M S^{\circledR} / D R I V E R$, Mechanical Dynamics, Inc., USA, 2002; http://www.adams.com/product/product_line/ driver.pdf.

73 Dvorak, P. Engineering puts virtual reality to work. Mach. Des., 1997, 69(4), 69-73.

74 Gomes de Sa, A. and Zachmann, G. Virtual reality as a tool for verification of assembly and maintenance processes. Computers and Graphics, 1999, 23, 389-403.

75 Jayaram, S., Connacher, H. I. and Lyons, K. W. Virtual assembly using virtual reality techniques. ComputerAided Des., 1997, 29(8), 575-584.

76 Arzi, Y. Methods engineering: using rapid prototype and VR techniques. Human Factors and Ergonomics in Mfg, 1997, 7(92), 79-95.

77 Solid Modelling, Slow Progress, The Business Advantage Group plc, April 2002; http://www.business-advantage. co.uk/Spaghetti/solidmodel.htm.

78 End-User Analysis: Mechanical CAD/CAM/CAE from the User Viewpoint, 1999 (Dataquest, USA).

79 Hsu, W. and Liu, B. Editorial - conceptual design: issues and challenges. Computer-Aided Des., 2000, 32, 849-850.

80 ADAMS $^{\circledR}$ Aerospace Solutions, Mechanical Dynamics, Inc., USA, 2000, p. 8.

81 Feng, S. C. and Zhang, Y. Conceptual process planninga definition and functional decomposition. Trans. ASME, Mfg Sci. and Engng, 1999, MED-Vol. 10, 97-106.

82 Williams, J. and Vemaganti, G. CFD quality - a calibration study for front-end cooling airflow. In Proceedings of the 1998 SAE International Congress and Exposition, SAE Special Publications Vol. 1318, February 1998, pp. 133-147 (Society of Automotive Engineers, Warrendale, Pennsylvania).

83 Wood, D. P. Comparison of modelled and actual car dynamic frontal crush. In Proceedings of the 1998 SAE International Congress and Exposition, SAE Special Publications Vol. 1319, February 1998, pp. 119-135 (Society of Automotive Engineers, Warrendale, Pennsylvania). 
84 Hetem, V. Communication: computer aided engineering in the next millennium. Computer-Aided Des., 2000, 32, 389-394.

85 Qamhiyah, A. Z. A strategy for the construction of customised design libraries for CAD. Computer-Aided Des., 1998, 13(11), 897-904.

86 Wang, Z. and Guan, C. Virtual rapid prototyping holography basis. Mfg Sci. and Engng, 1999, MED-Vol. 10, 171-174.

87 SpaceMouse ${ }^{\mathbb{R}}$, 3Dconnexion, Inc., USA, 2002; http:// www.3dconnexions.com/products/.

88 Ashteimer, P. and Gobel, M. Virtual design II: an advanced VR development environment. In Proceedings of Eurographics Workshops, Monte Carlo, Monaco, 1995.

$89 C A V E$, Visualization and Virtual Environments Group, National Center for Supercomputing Applications, USA, 2002; http://www.ncsa.uiuc.edu/Cyberia/VETopLevels/ VR.Systems.html.

90 PHANTOM ${ }^{\mathrm{TM}}$, SensAble Technologies, Inc., USA, 2002; http://www.sensable.com/haptics/products/phantom.html.

91 GHOST $^{\circledR}$, SensAble Technologies, Inc., USA, 2002; http:// www.sensable.com/haptics/products.html/ghost.html.

923 D Touch ${ }^{\mathrm{TM}}$, SensAble Technologies, Inc., USA, 2002; http://www.sensable.com/index.html.

93 Reachin $^{\mathrm{TM}}$, Reachin Technologies AB, Sweden, 2002; http://www.reachin.se/products/reachinapi/.

94 Balet, O., Luga, H., Duthen, Y. and Caubet, R. PROVIS: a platform for virtual prototyping and maintenance tests. In Proceedings of IEEE Computer Animation Conference, Geneva, Switzerland, 1997, pp. 39-47.

95 Bruns, F. W. Integrated real and virtual prototyping. In Proceedings of 24th Annual Conference of the IEEE Industrial Electronics Society, IECON, Aachen, Germany, 1998, Part 4, pp. 2137-2142.

96 Lu, S. C.-Y., Shpitalni, M. and Gadh, R. Virtual and augmented reality technologies for product realization. Ann. CIRP, 1999, 48(2), 471-495.

97 McQuay, W. K. A collaborative engineering environment for 21 st century avionics. In Proceedings of the 1998 IEEE Aerospace Conference (code 48731) of the IEEE Computer Society, 1998, Part 1, pp. 255-262.

98 Zha, X. F., Lim, S. Y. E. and Fok, S. C. Development of expert system for concurrent product design and planning for assembly. Int. J. Advd Mfg Technol., 1999, 15, 153-162.

99 Tsai, C. S., Chang, K. H. and Wang, J. Integration infrastructure for a simulation-based design environment. In Proceedings of Computers in Engineering Conference and the Engineering Data Symposium, ASME Design Theory and Methodology Conference, Boston, Massachusetts, 1995, pp. 9-20.

100 Ovtcharova, J. and Vieira, A. S. Virtual prototyping through feature processing. In Virtual Prototyping: Virtual Environments and the Product Design Process (Eds J. Rix, S. Hass and J. Teixeira), 1995, pp. 78-90 (Chapman and Hall, London).

101 Greipel, K.-P. and Colpaert, J. Dynamic and semantic modelling - a new approach to model products. In Virtual Prototyping: Virtual Environments and the Product Design
Process (Eds J. Rix, S. Hass and J. Teixeira), 1995, pp. 91-98 (Chapman and Hall, London).

102 Osman, T. A., Abdel-Aal, U. M., Elkenany, A. H. and Salem, F. Development of intelligent CAD for the design of mechanical systems. J. Engng Appl. Sci., 2001, 48(5), 937-953.

103 Sakamoto, S., Katayama T., Yokogawa, R. and Kimura, T. Construction of PC-based intelligent CAD system for cold forging process design - integration of CAD system and development of input method. J. Mater. Processing Technol., 2001, 119(1-3), 58-64.

104 Zuo, B. C. and Xu, L. D. An object-oriented intelligent CAD system for ceramic kiln. Knowledge-Based Syst., 2001, 14(5-6), 263-270.

105 Feijo, B. and Bento, J. Logic-based environment for reactive agents in intelligent CAD systems. $A d v$. in Engng Software, 1998, 29(10), 825-832.

106 Bento, J. and Feijo, B. Agent-based paradigm for building intelligent CAD systems. Artif. Intell. in Engng, 1997, 11(3), 231-244.

107 Eisenhard, J. L., Wallace, D. R., Sousa, I., De Schepper, M. S. and Rombouts, J. P. Approximate life-cycle assessment in conceptual product design. J. Ind. Ecology, 2000, 4(4), 61-82.

108 Asiedu, Y. and Gu, P. Product life cycle cost analysis: state of the art review. Int. H. Prod. Res., 1998, 36(4), 883-890.

109 Westkaemper, E., Alting, L. and Arndt, G. Life cycle management and assessment: approaches and visions towards sustainable manufacturing. Ann. CIRP-Mfg Technol., 2000, 49(2), 501-522.

110 Fiksel, J. Design for Environment: Creating Eco-efficient Products and Processes, 1996 (McGraw-Hill, New York).

111 Zhang, J., Chen, J. and El-Mounayri, H. A generic template for collaborative product development. Industrial virtual reality: manufacturing and design tool for the next millennium. Trans. ASME, Mater. Handling Div., 1999, 5, 163-170.

112 Andert Jr, E. P. and Morgan, D. Collaborative virtual prototyping and test. Nav. Engrs J., November 1998, $17-23$.

113 Lu, S. C.-Y., Cai, J., Burkett, W. and Udwadia, F. A methodology for collaborative design process and conflict analysis. Ann. CIRP, 2000, 49(1), 69-73.

$114 \mathrm{Java}^{\mathrm{TM}}$, Sun Microsystems, USA, 2002; http://java.sun. $\mathrm{com} /$.

115 Netscape $^{\circledR} \quad$ Navigator, Netscape Communications Corporation, USA, 2002; http://www.netscape.com/.

116 Internet Explorer ${ }^{\circledR}$, Microsoft Corporation, USA, 2002; http://www.microsoft.com/.

117 Gadh, R. and Sonthi, R. Geometric shape abstractions for internet-based virtual prototyping. Computer-Aided Des., 1998, 30(6), 473-486.

118 CATweb Navigator ${ }^{\mathrm{TM}}$, Dassault Systemes; http:// www.dsweb.com/solutions/html/catweb.htm.

119 Rowell, A. Virtual Models, Real Results, MCADvision, USA, July 2001; http://www.mcadcafe.com/MCADvision/ feature/virtual_models.html. 